\title{
E se a escola fosse nossa? Diálogos sobre sobre a realidade do pequeno grupo de pesquisas do colégio estadual João Barbosa Reis
}

\author{
Aliny Tinoco Santos \\ Antônio Santos de Oliveira \\ Letícia Nunes Andreatta \\ Luiz Gonzaga Roversi Genovese \\ Thiago Vasconcelos Ribeiro \\ Ualyson Toledo Carmo \\ Yuri dos Santos Siqueira
}

\section{Resumo}

Este texto foi construído sob forma de diálogos e consiste em uma tentativa de estabelecer uma identidade própria e específica à pesquisa escolar. Assim, pretende-se assumir a pluralidade de pontos de vista que são cotidianamente confrontados na compreensão e no enfrentamento de uma realidade social/educacional concreta: o Colégio Estadual João Barbosa Reis. A necessidade construída de, literalmente, "aparecer no texto" sob um nome próprio, não teve outra intenção, senão, apresentar ao leitor alguns recortes do contexto aqui objetivado na forma de pontos de vista diferentes, de modo a criar diferentes olhares em um único texto. Os agentes que aqui se discutem e refletem são provenientes das diversas posições sociais, tanto no espaço social quanto nos campos escolar e da escola e no campo universitário, consistindo basicamente em professores formadores da escola, licenciandos do curso de Física, e professores da Universidade Federal de Goiás, que tiveram a oportunidade de pensar essa realidade escolar concreta graças à construção coletiva de um Pequeno Grupo de Pesquisas - um ambiente diferenciado de formação inicial e continuada. Por intermédio deste exercício de reflexão crítica coletiva, foram identificados problemas que se encontram ali, simultaneamente, latentes e velados, devido às recorrentes desigualdades e tensões que se fazem presentes nessa realidade. O principal destes problemas, tomado como central nas discussões realizadas aqui neste trabalho, é o forte sentimento de exclusão que os alunos sentem no contexto escolar. A seguir, são sinalizadas algumas ações que estão sendo desenvolvidas na escola na tentativa de dar um melhor encaminhamento para essas problemáticas.

Palavras-chave: Pequeno Grupo de Pesquisas; Educação Básica; Formação de professores; reflexão crítica coletiva. 


\section{Introdução}

O presente texto, produzido de forma dialogada, consiste em uma tentativa de estabelecer uma identidade (forma) à pesquisa escolar, um bem simbólico produzido na e pela escola. Longe de querer ser, e querer parecer, uma produção de um ponto de vista universal, característico dos locais (posições) historicamente legitimados a objetivar um sem número de objetos - a universidade ou campo científico, por exemplo - a presente pesquisa não se esquiva em assumir a sua pluralidade de pontos de vista, todos aqui colocados e confrontados uns com os outros, com a finalidade de produzir conhecimentos sobre uma realidade social e educacional concreta: o Colégio Estadual João Barbosa Reis (JBR). Os autores dos discursos aqui expostos são professores formadores da escola, estagiários experientes e iniciantes e bolsistas do Programa Institucional de Bolsas de Iniciação à Docência (PIBID) que cursam licenciatura em Física e professores formadores da universidade que trabalham cooperativa, solidária e criticamente em Pequenos Grupos de Pesquisa (PGP) situados no campo escolar3 (GENOVESE; GENOVESE, 2012) como, por exemplo, no JBR, visando ressignificar tanto as disciplinas escolares quanto as disciplinas integradoras do curso de licenciatura em Física como os estágios e as práticas de ensino - da Universidade Federal de Goiás (UFG).

O colégio em questão onde foi construído o PGP está localizado na periferia da cidade de Aparecida de Goiânia, região metropolitana de Goiânia. A unidade de ensino oferece à comunidade as modalidades de ensino fundamental de ciclo II e ensino médio no turno matutino, ensino fundamental de ciclo I no turno vespertino e ensino médio e Educação de Jovens e Adultos (EJA) no turno noturno. Desde agosto de 2015, procura-se estabelecer no colégio uma relação mais horizontal entre o campo escolar e o campo universitário, por meio da qual os professores formadores do campo escolar desempenham um papel fundamental na construção e manutenção do PGP, que tem como principal objetivo promover a formação inicial e continuada de professores da escola, licenciandos do curso de física - estagiários experientes e iniciantes e bolsistas do PIBID - e professores pesquisadores da universidade. Porém, essa descrição formal e genérica foi produzida pelo campo universitário e seus agentes (GENOVESE; GENOVESE, 2012) que, por sua vez, cria um afastamento não desejável entre os agentes do campo escolar e do campo universitário. Nesse sentido é necessário avançar para a construção coletiva de uma representação do JBR que de fato leve em consideração os agentes que ali estão inseridos, e que seja capaz de propor encaminhamentos mais significativos às urgências e aspectos dessa escola que exijam uma investigação mais profunda.

\footnotetext{
3 O campo escolar é um campo de forças relativamente autônomo constituído pelas escolas, públicas e privadas, dotado de uma estrutura de distribuição de capitais simbólicos específicos e reconhecidos pelos agentes que nele estão inseridos, sendo essa distribuição responsável pela hierarquização das escolas e dos professores segundo a sua lógica específica de funcionamento e que comandam os atos de investimento e as estratégias de luta no interior desse espaço. (GENOVEZ, 2008; GENOVESE, 2014), 
$\mathrm{Na}$ intenção de estabelecer um meio de reflexão que valorize o conhecimento específico produzido na escola, foi construída uma metodologia de escrita para o presente texto, introduzindo algumas características peculiares capazes de contribuir de forma imprescindível para a reflexão proposta. A principal delas talvez seja a escolha em se dar um nome e um ponto de vista para cada um dos agentes que vivem e refletem coletivamente aquela realidade, quer dizer, a necessidade de, literalmente, "aparecer no texto" sob um nome próprio e uma posição tomada (as vezes consciente, as vezes não) que não teve outra intenção senão apresentar ao leitor alguns recortes da realidade aqui objetivada - que, devido à reflexividade exercitada, por vezes confunde-se com a objetivação dos próprios autores - sob a forma de pontos de vista diferentes, de modo a criar diferentes olhares em um único texto. Desafiamos, com isso, o leitor(a) a assumir uma postura mais ativa e participativa - isto é, ir além do papel de leitor passivo -, apropriando-se do exercício de construir para si o cenário que aqui é discutido e problematizando, a partir de sua própria posição seja no campo escolar seja no campo universitário ou em qualquer outro. O presente texto consiste, ainda, em um exercício de construção de uma identidade não só pelo leitor, que, como já foi dito, recebe aqui a missão de "ligar os pontos", apreender os recortes e extrair-lhes um significado, obviamente situado; mas também o é para os seus próprios autores que o utilizaram como ferramenta de (auto)objetivação e (auto)compreensão. Novamente, a pesquisa aqui proposta não possui pretensão de universalidade (inalcançável), tal qual a pesquisa tradicional incessantemente busca, mas sim o de proporcionar - ou permitir o acesso, ao menos - a uma pluralidade de perspectivas, que nada mais são, senão, diferentes olhares, situados tanto no campo escolar quanto no campo universitário, sobre um mesmo objeto e, assim, construir um conhecimento sobre: uma escola pública concreta, com problemas específicos em um contexto específico. Uma vez assumido essa espécie de “contrato" entre autores e leitores, passemos agora ao cerne do texto em si, os posicionamentos e pontos de vista sobre essa realidade escolar.

\section{(Des)Construindo Uma Realidade}

Thiago4: À primeira vista, lecionar no JBR não parece ser, de modo algum, um trabalho fácil. Seja pelo lugar onde está localizado, o Conjunto Habitacional Madre Germana I, um bairro afastado em Aparecida de Goiânia, caracterizado essencialmente pelas suas recorrentes ausências, seja pela unidade de ensino ser um espaço social que reúne - isto é, põe junto, em convivência direta - agentes que trazem consigo toda a diversidade de valores presente ali na região, o colégio é um desses lugares que convergem as latentes tensões que acompanham a sobrevivência cotidiana (BOURDIEU, 2012). Nesse sentido, quais foram as impressões mais marcantes ao adentrar nesse local buscando uma formação

\footnotetext{
4 Professor voluntário do PGP-João Barbosa Reis.
} 


\section{docente?}

Aliny5: Meu primeiro contato com a região onde a escola está localizada ocorreu antes mesmo de cursar o ensino superior, na minha adolescência, quando participei de um projeto social em uma escola conveniada bem próxima ao JBR. Por residir em um bairro muito próximo à região da escola, eu não senti esse impacto ou essa estranheza (muito comum aos visitantes) devido a distância com que ambos os bairros estão localizados em relação a região central de Goiânia. E por nunca ter presenciado nenhuma cena de violência ou coisas do tipo, que muitas vezes permeiam os noticiários quando retratam as "notícias da região", seja da escola seja do local onde moro, não havia tão forte em mim o preconceito que outras pessoas - geralmente "forasteiros" - demonstram quando escutam referências ao bairro e a sua fama de "região perigosa". As próprias características do bairro, o arranjo das casas, das ruas fontes de algumas estranhezas ao olhar externo - me eram (e são) muito naturais. Aliás, destaco aqui a forma como o bairro é organizado, e até bem estruturado, pois conta com água encanada, posto de saúde, posto policial; recursos que não estavam presentes no bairro em que moro quando fiz meu primeiro contato com o "Madre Germana I". Mesmo assim quando fui chamada para lecionar no JBR, a minha primeira experiência como professora regente, no início do ano 2014, fiquei com medo (principalmente no turno noturno); mas depois de conhecer a realidade dos alunos tanto do turno noturno quanto do matutino, percebi que medo não era o sentimento que deveria sentir por eles (e com eles), mas sim solidariedade.

Thiago: Para mim, o primeiro impacto, aquela estranheza mais evidente do primeiro contato com a escola, que te faz imaginar como se dá a educação na rotina daquele lugar, foi o desgaste da estrutura física. As cadeiras quebradas. Os pisos irregulares, deteriorados. A limitada iluminação, devido à ausência de lâmpadas. Carências aparentemente básicas que contrastam com o esforço das pessoas que ali trabalham em tornar o lugar mais acolhedor e humano. A decoração presente no jardim da entrada da escola; o colorido, mesmo que desgastado, das grades da entrada dos alunos; os murais no pátio com recados para os alunos; a decoração da sala dos professores; são todas, de alguma forma, manifestações de resistência àquele ambiente que insiste em querer se tornar hostil tanto para alunos quanto para professores.

Ângelo ${ }^{6}:$ Realmente, o contraste entre uma estrutura física degradada e um corpo docente que busca tornar esse lugar mais familiar e acolhedor foi o que mais me chamou a atenção ao entrar na escola pela primeira vez, mas com o passar do tempo e mesmo que com algumas diferenças, eu pude me reconhecer dentro daquela escola, pois estudei todo o meu ensino fundamental em um colégio estadual em condições semelhantes. Mesmo que eu pareça

\footnotetext{
5 Professora formadora do PGP-João Barbosa Reis.

${ }^{6}$ Estagiário e bolsista do PIBID do PGP-João Barbosa Reis. 
um pouco deslocado como professor me senti muito bem acolhido tanto por professores como por alunos, isso pode ser reflexo da carência que a escola tem para ser reconhecida e se reconhecer como formadora de cidadãos.

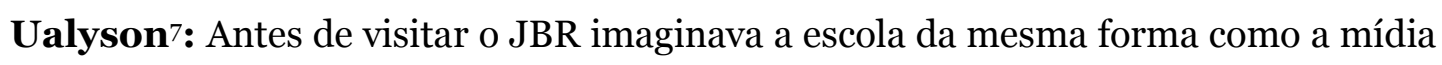
retrata o lugar, marginalizado, violento, porém, quando conheci os alunos percebi que a realidade deles não era tão diferente da minha. O que nos difere é a oportunidade de estudar em uma escola dita "exemplar", já que tive a oportunidade de estudar em um colégio militar, com acesso a recursos mais privilegiados para o aprendizado. Já o bairro onde moro se assemelha muito como o "Madre Germana I", porém não possui creche, colégio estadual ou municipal, o que me obrigou a me deslocar para outras regiões de Goiânia para estudar. Outra coisa que me chama a atenção até hoje é a visão que meus pais têm dos alunos sem nem mesmo conhecê-los. Eles me dizem para não ser muito próximo dos alunos pois se alguém me vir com eles podem pensar que eu "sou da turma deles" ou amigo deles e, segundo meus pais, podem achar que sou um "mala" como os alunos. Não preciso nem dizer que não concordo com isso. Olhar para os alunos do JBR, sem conhecer o lugar, é como olhar uma pessoa por uma vidraça suja, o que é sujo não é a pessoa, mas o meio que eu uso para enxergá-la.

Yuri8: O "susto" não foi muito grande devido a experiências antecedentes - por já ter trabalhado em uma escola pública estadual -, exceto com relação ao que tange a "liberdade" da escola que é bem ampla, tanto dos alunos no qual o seu direito de ir e vir é mais irrestrito, quanto dos professores que "entram e saem" da escola - alguns professores por serem contratados temporariamente, outros simplesmente por desistirem da profissão -; sem muita demora se percebe isto. Desde meu ingresso no curso de licenciatura em Física na UFG percebo um certo tipo de abismo que separa os vários motivos que levam um alguém a querer este tipo de curso. No que se trata do JBR, parece que aqueles que adentraram ao curso afins de se sentirem desafiados e necessários encontrarão lá o que procuram, talvez em demasia.

Luiz9: Antes de expressar minhas impressões sobre o JBR, gostaria de destacar uma preocupação, mais ligada a posição de professor de estágio na perspectiva do Grande Grupo de Pesquisa (GENOVESE, 2013) ${ }^{10}$ e seus Pequenos Grupos de Pesquisa e de pesquisador (não sei se se autodeclarar pesquisador é suficiente para ser pesquisador, e muito menos gostaria de ser associado a certos tipos de entendimentos dominantes sobre o que é ser pesquisador) periférico no campo da pesquisa em Ensino de Ciências e Matemática. A saber, o JBR era um lócus que pudesse ter vínculo subjetivos e objetivos com a professora formadora Aliny e

\footnotetext{
7 Estagiário e professor do PGP-João Barbosa Reis.

8 Estagiário do PIBID do PGP-João Barbosa Reis.

9 Professor Doutor, do Instituto de Física da Universidade Federal de Goiás- Professor da disciplina de estágio.

${ }^{10}$ GENOVESE, L. G. R. Obstáculos à Consolidação da Relação entre o Campo Escolar e o Campo Universitário: os Pequenos Grupos de Pesquisa de Goiás em foco. In: Encontro Nacional de Pesquisa em Educação em Ciências, Águas de Lindóia, 2013. Atas... Águas de Lindóia, 2013. p. 1-8.
} ISSN 2526-2882 
licenciandos formadores experientes e iniciantes e/ou bolsistas do PIBID e, assim favorecer o envolvimento dos mesmos para o enfrentamento dessa realidade social.

Satisfeita essa preocupação, indico que as minhas impressões se resumem, primeiro, a grande distância entre a UFG e o PGP-JBR e, segundo, a receptividade e acolhimento dos alunos fragilizados econômica e culturalmente (em relação à cultura legítima) do JBR para comigo, um estranho. Tais impressões com marcas de compreensão e auto compreensão (o quão longe socialmente estou dos alunos do JBR? Que violências simbólicas exerço sobre eles?...) me fizeram ser mais solidário com meus alunos de estágio e PIBID, que moram na região e desenvolvem seus PIS no JBR, pois evidenciaram a distância social, cultural e econômica entre nós.

Letícia'1: Eu estudei a vida inteira em escola particular e o primeiro contato que realmente tive com uma escola pública foi no meu primeiro ano de estágio, no período noturno, no Colégio Estadual Cora Coralina, situado na Vila Redenção, em Goiânia. O colégio tinha muitos alunos que entravam e saíam da prisão toda semana, além de se presenciar, com alguma frequência, pessoas usando drogas nas proximidades do colégio. Mesmo assim eu não tinha medo dos alunos ou da escola, mas sim de pegar ônibus para ir e voltar para casa. A mesma coisa aconteceu em relação ao JBR, a primeira vez que fui para a escola eu fiquei com medo pela fama do setor (já que todos os meus familiares falavam sobre o quanto o "Madre Germana I" era perigoso), mas quando eu entrei na escola o medo passou e eu me concentrei na realidade da mesma. A primeira coisa que percebi foi o quanto a escola precisava de ajuda, não só pela questão da estrutura (salas de aula com apenas uma lâmpada, construídas com paredes de placa, janelas quebradas, etc.), mas também pelos alunos e professores. Quando nos firmamos na escola tive a sensação de estar em casa, no sentido de que, após passar por vários PGP, eu finalmente tinha encontrado um colégio no qual eu poderia fazer a diferença, mudar a vida dos alunos, dos professores e gestores da escola para melhor e deixar uma contribuição significativa para o colégio.

Thiago: Nós temos que tomar cuidado com o discurso que diz que a "escola precisa de ajuda”. A primeira impressão do JBR pode nos levar a acreditar nisso, porém, o colégio funciona e já funcionava muito antes de nós o conhecermos. Para o bem ou para o mal, é uma instituição que outorga (ou certifica) a aquisição de determinada parcela de capital cultural, necessária para se viver em sociedade. Pode-se argumentar contra isso, afirmando-se que o JBR não se trata de um colégio capaz de promover uma mudança ou ascensão social aos seus alunos e, por isso, precisa de ajuda. Entretanto, escola alguma parece ser capaz de proporcionar mudanças sociais, mas, pelo contrário, consistem em eficazes mecanismos de manutenção da hierarquia social (BOURDIEU, 2010; BOURDIEU; PASSERON, 2014).

\footnotetext{
${ }^{11}$ Estagiária e bolsista do PIBID do PGP-João Barbosa Reis.
} 
Lembro-me de ter visto uma crítica semelhante em um documentário sobre os efeitos da inserção do sistema escolar em um país dito subdesenvolvido ${ }^{12}$ cuja educação tradicionalmente se dava por outras vias. O argumento da ajuda - e da necessidade de ajuda - justificava a ação acrítica dos gestores escolares (profissional ou voluntariamente envolvidos) sobre a realidade analisada, de modo que os problemas associados à essa "ajuda" realizada permaneciam ocultos, dissimulando um verdadeiro massacre cultural. Claro que acredito que as nossas ações não vão nessa direção, tão pouco possuem essa intenção. Apenas quero deixar o alerta para os riscos associados ao se tratar aquela realidade ou seus alunos e professores como algo ou alguém que "precisa de ajuda" - que é perigosamente próximo da conclusão "eles são incapazes de ajudarem a si próprios" - e que se torna um obstáculo ao desenvolvimento de um diálogo realmente crítico com eles. O cuidado em respeitar aquilo que a escola e os seus agentes valorizam é essencial neste processo. Logo, a verdadeira ajuda que realmente importa para a escola é a de fomentar a reflexão sobre a própria realidade, suas práticas e seus problemas e a ação transformadora.

Luiz: Eu diria que para evitar essa abordagem assistencialista, seria necessário compreendermos a posição da escola no interior do campo escolar e o campo da escola, sem se esquecer de localizar as frações de classe que pertencem os alunos e nós. Para aí sim, trabalharmos nesse processo compreensão mútua dos mecanismos ocultos de dominação...

Ualyson: A estrutura (todos nós concordamos), mas também o sentimento por parte dos alunos de não pertencer àquele ambiente, o abandono de algumas dependências da escola tais como a sala de informática e a biblioteca, a usurpação de outros espaços (podemos ver isso na horta da escola, por exemplo), são de forma geral as carências que nós observamos até agora. Além dessas podemos notar, ainda, a carência dos alunos, os problemas que alguns enfrentam fora dos muros da escola (de cunho familiar, pessoal, profissional, etc.) e que, de uma forma ou de outra, convergem para a sala de aula.

Letícia: Uma carência mais sutil e talvez não tão importante quanto as outras é a questão da união, uma vez que os professores e os gestores acabam competindo entre si mais do que enxergando a profissão e o campo escolar como um espaço que requer o trabalho em grupo.

Ualyson: O que a Letícia disse sobre união é bem visível durante as reuniões dos professores. Entretanto acredito que a desunião é consequência da falta de vontade por parte de alguns professores, que não querem se mobilizar e acreditam que a educação se resume a sala, quadro e giz. Falo isso pois alguns professores compreendem a necessidade de uma

\footnotetext{
${ }^{12}$ Escolarizando o Mundo: o último fardo do homem branco. Direção: Carol Black. Produção: Jim Hurst, Mark Grossan, Neal Marlens. [Telluride]: Lost People Films, 2010. Título original: Schooling the World: The White Man's Lats Burden. Disponível em: https://www.youtube.com/watch? v=6t HN95-Urs Acesso em: 23 mar. 2016.
} ISSN 2526-2882 
formação que vai além da sala de aula, uma educação que politize o aluno, que o faça compreender o que é estar em sociedade.

Yuri: Acredito que não haja uma falta de carência em lugar algum no mundo seja questão de carência material ou de espírito, pois isto me parece ser algo que se relativiza diante das diferentes perspectivas que se tem da mesma "realidade". Todavia o JBR chama a atenção no quesito carência, mas nem por isso devemos superestimá-la, a partir do momento em que se há espaço para ser "auto suficiente" pode-se ser auto suficiente, quando se há o mínimo necessário existe simultaneamente a possibilidade de se poder fazer o melhor possível, e no quesito mínimo o JBR parece ficar com menos.

Thiago: A carência levantada pelo Ângelo anteriormente parece ser uma forma de carência "resultante", que reúne todas aquelas carências individuais e coletivas que se fazem presentes na escola: a carência que o JBR possui em reconhecer a si mesmo e para ser reconhecido pelo espaço social como um lugar capaz de formar cidadãos. Essa carência que, assim como todas as outras, é o resultado e o motor dos inúmeros conflitos sociais do qual a escola é lugar, se manifesta na rotina escolar sob a forma de tensões diárias produzidas pelas urgências decorrentes do contato direto com as misérias locais (as drogas, a desestrutura familiar, a violência, a ausência e o desconhecimento de direitos, etc.), e as recorrentes necessidades de responder a demandas provenientes de instâncias burocráticas maiores, como a secretaria da educação, que impõem a sua política praticamente sem diálogo algum com qualquer agente da escola (e que é bastante reforçada pelos "cúmplices" que atuam no interior da própria escola). Essas tensões frequentemente resultam em posturas contraditórias de professores e administradores da escola que ora parecem abertos ao diálogo e às mudanças, ora impõem aos alunos aquelas demandas que lhes são diretas e externamente impostas.

A realidade social e escolar do JBR aqui discutida foi cuidadosamente pensada e considerada quando se foi cogitado a construção do PGP ali e, principalmente, sobre as contribuições em se realizar todo um processo de formação inicial e continuada de professores naquelas condições em específico. Escolher como ambiente de estágio esse local de extremos tão evidentes não possui outra finalidade senão formar professores que consigam se organizar e se articular coletivamente para o enfrentamento de uma realidade concreta. Dito isto, a seguir são relatados os principais enfrentamentos feitos pela professora formadora em um período anterior ao da instauração do PGP-JBR.

\section{Enfrentamento da Realidade dentro da Escola}

Aliny: Me tornei professora do JBR em março de 2014 enquanto ainda concluía o curso de licenciatura em física na UFG. A rotina de estudar e trabalhar não foi novidade para 
mim, uma vez que esta durou quase todo o curso, apenas com a diferença que o meu trabalho anterior era extremamente mecânico e burocrático - atendente do serviço de atendimento ao contribuinte da prefeitura da cidade onde moro. Saí deste emprego para tentar me dedicar mais ao curso e reduzir o atraso nas disciplinas, mas só consegui me afastar por um ano, devido as dificuldades financeiras que minha família e eu enfrentamos. Diante disso, decidi que se precisava realmente trabalhar seria na área a qual estava me formando - a docência.

Letícia: Aliny, após esse ano sem trabalhar, como você foi trabalhar no JBR?

Aliny: Entreguei currículos diretamente nas subsecretarias estaduais de educação dos municípios de Goiânia e Aparecida de Goiânia e logo entraram em contato por meio de telefonema, para oferecer 10 aulas de física no turno noturno e 18 aulas de matemática no turno matutino, no JBR. Eu não tinha nenhuma experiência como professora regente e ainda precisei me preparar para lecionar uma disciplina (matemática) que, apesar de não ter dificuldade, eu não conhecia as sequências didáticas mais adequadas ou metodologias diferentes, por isso fiquei muito insegura.

Thiago: Então, naquele momento você se tornava professora sem estar formada. Aparentemente, uma realidade bastante comum na educação pública brasileira. Tornara-se professora na prática, no enfrentamento daquela realidade problemática, tendo que lidar com o ensino da disciplina de matemática, apesar de cursar Licenciatura em Física. Sem contar com experiência alguma deste tipo, como foi que você conseguiu enfrentar as dificuldades relativas a essa condição, de certa forma, urgente e desafiadora?

Aliny: No turno noturno as principais tribulações eram a baixa frequência dos alunos e a dificuldade que eles tinham com a matemática. Tentei ensinar com se calculava a quantidade de cargas elétricas para os alunos de uma turma de terceiro ano, porém repeti os mesmos cálculos quatro vezes de maneiras diferentes, mas os alunos não conseguiam se lembrar na aula seguinte. Por esse motivo, e para conseguir avançar com os conteúdos, buscava sempre focar mais nos conceitos do que nas fórmulas. Busquei também apresentar experimento para eles e ainda propus que eles mesmos elaborassem experimentos para apresentarem para os colegas. Trabalhei com os alunos a montagem de miniplanetários, motores homopolares com imãs de autofalantes de fones de ouvido velhos, experimentos de eletrostática com canudos-versorium, sempre tentando dar o máximo de liberdade e estimular que eles propusessem modificações.

Em relação ao esforço para me adaptar no turno noturno, a principal dificuldade era devido ao número baixo de aulas e, portanto, a minha pouca presença na escola. Eu ia apenas dois dias por semana na escola e, assim, não conhecia a maioria de meus colegas, quase sempre perdia as informações passadas no turno. Muitas vezes chegava na escola e estava acontecendo algum evento, ou não haveria aula e a maioria dos professores eu só via em dias de conselho 
de classe. Mas por se tratar de um grupo menor de professores, mais receptivos, não foi difícil me integrar ao grupo. A diretora era bem ausente, porém a coordenação conseguia controlar os alunos muito bem, o que me passava uma segurança maior.

No turno matutino meus esforços eram de outra ordem. Eu precisava ensinar matemática, conteúdos obrigatórios de um currículo proposto (ou melhor, imposto) pela secretaria de educação do estado, porém os alunos não dominavam o mínimo necessário para avançar com o conteúdo. A solução que eu encontrei foi fruto de uma coincidência, porque a escola possuia uma parceria com uma instituição particular que oferecia o apoio de uma pessoa, uma vez por semana. Essa pessoa estava trabalhando jogos matemáticos com as turmas que eu havia assumido. Portanto, devido a essa relação, comecei a trabalhar com jogos nas minhas aulas de matemática e consegui obter resultados interessantes. Infelizmente, a parceria se encerrou em abril de 2014, mas eu tentei continuar essa prática porque percebi que era eficaz: os alunos participavam e se aproximavam cada vez mais de mim.

Além disso foram discutidos alguns assuntos que surgiram nos noticiários, nas redes sociais e que por vezes eram trazidas pelos próprios alunos e outras por mim, mesmo fora do conteúdo obrigatório. Esses assuntos que possuem explicações científicas precisam ser discutidos, primeiramente porque se tornam de interesse dos alunos, uma vez que todos estavam comentando, mas, também, porque é fundamental que o professor esclareça aos alunos sobre algumas versões equivocadas dos verdadeiros fenômenos divulgados.

A escola exige que o papel do professor vá além do papel de apenas ensinar o currículo, mas que diversas vezes precisamos manter uma relação pessoal, afetiva. Não são raras as vezes que precisei agir como psicóloga, escutando e dando conselhos sobre questões da vida pessoal de alunos. O envolvimento do professor com as atividades da escola é uma relação carregada de responsabilidades que exigem certo traquejo e muitas habilidades como, por exemplo, as ocasiões em que precisei ensinar os alunos a cantar e dançar, montar salas temáticas sobre regiões do país, folclore, consciência negra, colaborar com a produção de um livro sobre o cerrado.

Já com os professores o impasse era maior. Diferente do noturno, no turno matutino eu estava na escola todos os dias, mas a convivência era bem mais difícil. Haviam grupos de afinidade pessoal entre os professores, muito falatório, uma coordenação mais difícil de lidar. Com o passar do tempo consegui ir me posicionando, conhecendo os professores, realizando meu trabalho e participando das atividades propostas pela escola, e a convivência foi ficando cada vez mais tranquila

Ângelo: Professora, percebo que conseguiu encontrar diversas alternativas para levar a ciência para mais próximo dos alunos, e eu, (ainda) como estudante e pretenso professor, fico me indagando se a Universidade está realmente nos preparando para essa 
realidade. De onde tirou ideias para solucionar os problemas de forma prática e que sustentasse o interesse dos alunos? Foi da própria Universidade ou foi um aprendizado prático dentro da própria escola?

Aliny: Bom Ângelo, entendo que a nossa formação, ou como Bourdieu chama, a construção do nosso habitus ${ }^{13}$, de Homo magister ${ }^{14}$, vem das diversas experiências pelas quais nós passamos. A universidade realmente não nos forma para a lidar com a maioria das adversidades que nos deparamos na escola. Mas também precisamos lidar com situações inéditas que ainda não havíamos vivido na escola. Em meu Trabalho de Conclusão de Curso (TCC) analisei algumas demandas que foram surgindo durante a minha prática enquanto estagiária e pude perceber como os habitus são mobilizados em algumas situações. Nesses casos, muito do habitus ao qual precisamos recorrer foi construído em nosso dia a dia, em casa, em nossas experiências enquanto alunos. Tais experiências são de grande importância para a formação de professores.

Luiz: Gostaria de lembrar para alguns e informar para outros que a professora formadora Aliny, nos anos de 2011 e 2012, participou do PGP-Goainy Prates. Nesse PGP, um dos primeiros a serem construídos, teve oportunidade e experiência de lecionar no EJA, mas como estagiária iniciante que foi acolhida pelo estagiário experiente Danillo Deus Castilho e o Professor Supervisor Carlos Eduardo Cruz e Silva. Situação distinta da atual.

Ualyson: Aliny, quais foram as maiores diferenças que você notou entre ser estagiária, professora sem graduação completa e professora com graduação completa, dentro do campo escolar e do campo da escola?

Aliny: Eu consigo perceber a diferença de cada uma dessas etapas da nossa formação, pois o estágio é uma situação especial e idealizada porque nos possibilita uma intervenção, porém com menos envolvimento com os alunos, sem uma pressão burocrática de planejamento de aula, fechamento de nota, entre outras coisas. O estágio é necessário e é decisivo para que o aluno perceba se ele realmente se vê no futuro exercendo aquela profissão. Porém quando assumimos uma turma como professor regente o nosso envolvimento é maior seja graduando ou graduado. A diferença que eu poderia destacar seria de que quando estamos formados recebemos um reconhecimento diferenciado tanto por parte dos professores como dos alunos, e ainda, não temos a preocupação com as disciplinas da graduação. A nossa profissão requer de nós uma dedicação muito grande, inclusive extraclasse e por isso enquanto dividimos as

\footnotetext{
13 Bourdieu define habitus como sendo um conjunto de "sistemas de disposições duráveis e transponíveis, estruturas estruturadas predispostas a funcionar como estruturas estruturantes, ou seja, como princípios geradores e organizadores de práticas e de representações que podem ser objetivamente adaptadas ao seu objetivo sem supor a intenção consciente de fins e o domínio expresso das operações necessárias para alcançá-los, objetivamente "reguladas" e "regulares" sem em nada ser o produto da obediência a algumas regras e, sendo tudo isso, coletivamente orquestradas, sem ser o produto da ação organizadora de um maestro" (BOURDIEU, 2011, p. 87).

${ }^{14}$ Habitus característico do professor da educação básica (GENOVEZ, 2008).
} ISSN 2526-2882 
atenções entre universidade e escola muitas vezes negligenciamos algumas coisas. Pelo menos foi assim comigo, uma vez que me sinto muito mais dedicada à escola depois que conclui o curso.

Thiago: O Pequeno Grupo de Pesquisa do Colégio Estadual João Barbosa Reis (PGP-JBR), neste contexto, pretende ser um espaço de formação de educadores reflexivos, capazes de se articularem e se organizarem coletivamente ao tornar a reflexão sobre a própria prática docente e sobre a prática escolar como um todo, o ponto de partida para uma fundamentação e uma conscientização crítica dos enfrentamentos, individuais e coletivos que se fazem presentes tanto em sala de aula quanto na escola. Uma das propriedades pertinentes na logística desenvolvida por um PGP consiste no fomento a ambientes de debate e reflexão crítica como um mecanismo de identificação de verdadeiros problemas - por oposição aos falsos problemas (BOURDIEU; CHAMBOREDON; PASSERON, 2010), problemas aparentes e de aparência, que produzem a sensação ilusória de que são evidentes, dados, e que frequentemente se associam problemáticas incontornáveis, contribuindo para a construção de uma realidade fatalista, imutável e completamente alheia aos seus participantes - presentes na escola, as suas gêneses históricas e as suas implicações para a construção do contexto concreto e histórico em que todos os agentes estão inseridos e simultaneamente contribuem para essa construção.

Aliny: Por não perceber o potencial formativo desse espaço e por ter receio de, não encontrar pessoas dispostas a ir até ao JBR fizemos a primeira tentativa de construir um PGP no Colégio Estadual Novo Horizonte-NH, colégio localizado em Goiânia, mais próxima da região central, isso porque tive receio em não encontrar pessoas dispostas a ir até ao JBR. Porém, ainda que tenhamos tentado inicialmente formar um o PGP no NH, muitos fatores impediam o desenvolvimento do grupo neste colégio, como por exemplo a falta de interesse por parte da direção da escola para com as atividades que estávamos realizando na escola. Esse afastamento fez com que, apesar já ter exposto para todos os alunos de estágio e PIBID as inúmeras dificuldades que eu enfrentava/passava no JBR, todos eles concordaram em tentar levar a proposta do PGP para lá. Em nenhum momento o corpo a escolar demonstrou resistência à vinda dos estagiários, pelo contrário, a diretora, por exemplo, se mostrava eufórica, ansiosa, esperançosa, feliz, sempre que eu falava da possibilidade da vinda deles para o JBR.

Thiago: Mas não foi somente o JBR quem ganhou com a construção do PGP naquela escola. Lembro-me de muitas incertezas que você tinha quanto ao andamento dos trabalhos realizados com os estagiários lá no $\mathrm{NH}$ e como as suas conversas sempre faziam um paralelo com a realidade sua vivida no próprio JBR. Acredito que o principal motivo de você escolhido desenvolver os trabalhos do PGP no JBR se deve principalmente pelo seu próprio 
envolvimento ser um tanto maior naquela escola quando comparada ao seu envolvimento no NH. Não digo envolvimento no sentido de dedicação ao trabalho ou ao ensinar, propriamente dito, mas sim no sentido bourdiesiano de "aposta". As apostas realizadas no JBR, naquela época e ainda hoje, são, a meu ver, as suas principais apostas enquanto professora da educação básica. Eu estou errado em minha observação? A seu ver, quais foram os fatores que levaram com que as suas apostas realizadas enquanto professora se orientassem à realidade específica do JBR?

Aliny: Acredito que as apostas começam a partir da minha identificação com os alunos, pois também sou de uma família originalmente de classe baixa, estudei minha vida inteira em escola pública e por muitas vezes fui oprimida com discursos de segregação e não percebia isso. Também me identifico com a escola e os alunos pois valorizo o capital social assim como a escola ${ }^{15}$ e a partir de uma compreensão dos valores desse capital percebo que ele é capaz de promover tipos de aprendizagem além de ser possível converter o capital social em capital cultural. A abertura que o capital social promove e que gera um tipo de relação de confiança entre professor e aluno me permitiu realizar várias intervenções pedagógicas junto aos alunos. Pude observar isso, por exemplo, quando levei um labirinto elétrico e pedi para que os alunos tentassem reproduzir o circuito em um desenho: os alunos do JBR brincaram com o experimento, desenharam, perguntavam como funcionava e queriam fazer um igual, ao passo que os alunos do $\mathrm{NH}$ questionaram minha metodologia porque ela não seria cobrada no Exame Nacional do Ensino Médio- ENEM.

Thiago: Então a questão do ajustamento entre o habitus do professor e os capitais valorizados pela escola são importantes fatores que influenciam as estratégias docentes em sala de aula e fora dela. Mas onde entram os estagiários? Que tipo de capital eles são? Cultural ou social?

Luiz: Nessa linha penso nos processos formativos ou não oriundos do ajustamento e desajustamento entre o habitus da professora formadora Aliny e dos estagiários. Aí está um grande desafio para a formação. Né!

Aliny: Com certeza eles promovem os dois tipos de capital. O capital social foi o primeiro a ser percebido, mesmo quando eles ainda não frequentavam o colégio, uma vez que depois que informei a diretora e a coordenação (do JBR) da possível participação de estagiários do curso de física da UFG, elas começaram a me destacar diante dos colegas, me citar como

\footnotetext{
15 Vários elementos podem ser destacados como evidências de acúmulo de capital social dentro da escola: a realização recorrente de eventos, alguns deles sem tanta relação com o currículos tradicionais disciplinares; a preocupação em convidar pessoas de fora da escola para presenciarem os eventos ali organizados (geralmente pessoas da Secretaria de Estado da Educação; valorização da participação da escola em eventos envolvendo outras escolas estaduais; tentativa de envolver os alunos nos eventos sempre valorizando os talentos artísticos que eles possuem; preocupação em estimular os professores da escola em desenvolver uma relação afetiva mais próxima com os alunos; dentre outros.
} 
exemplo entre outras coisas. No próprio $\mathrm{NH}$, ao conversar com o diretor sobre a minha possível contratação, informei que o meu interesse era o de possibilitar um campo de estágio para esses alunos e o diretor se mostrou bem interessado. Já o capital cultural é percebido principalmente porque os estagiários são possivelmente o contato mais próximo que esses alunos têm com a universidade, além de eles proporem estratégias didáticas que atraíram os alunos para a busca de conhecimentos.

Thiago: Portanto, os próprios estagiários consistem em capitais simbólicos mais valiosos para a professora formadora no contexto do JBR. Aparentemente, a presença de estagiários não perturbava tanto a rotina escolar no $\mathrm{NH}$ e não garantia à professora Aliny o reconhecimento no interior da escola, necessário para se realizar enfrentamentos mais profundos e delicados. O peso simbólico de que a presença dos estagiários proporciona à própria posição da professora no campo da escola parece-me ser muito mais intenso no JBR, o que autoriza, de alguma forma, a ação coletiva dos integrantes do PGP em problemas mais estruturais daquele contexto. Dito de outra forma, essas duas situações antagônicas (a receptividade do $\mathrm{PGP}$ e dos estagiários no $\mathrm{NH}$ e no JBR) evidenciaram principalmente que o PGP somente é capaz de se firmar na escola se for percebido como uma forma de aposta tanto pelo(a) professor(a) formador(a) quanto pela própria escola.

Ualyson: O próprio reconhecimento por parte da escola de que estamos lá evidencia isso. No dia da elaboração do Projeto Político Pedagógico-PPP- do JBR, ao nos apresentar, uma das coordenadoras disse: "Eles não são mais os meninos da Aliny, eles são os meninos do $J B R$ ”, isso me marcou, pois, a escola, os professores, os alunos reconhecem-nos como parte daquele lugar, talvez não com a mesma força, mas há um apreço pela presença do PGP.

Thiago: Durante as reuniões do PGP, discutindo principalmente as aulas da professora Aliny, percebemos um problema aparentemente recorrente, no comportamento e diálogos presenciados na sala de aula e na escola: os alunos têm um sentimento e uma percepção de que a escola não é algo que pertença a eles. Trata-se de um sentimento de exclusão que reside numa espécie de presença negada daquilo que a escola poderia (deveria) oferecer. Esse sentimento de exclusão tem origem e é reforçado em muitas das ações cotidianas da escola, tornando-a num espaço em que os mesmos são obrigados a permanecer durante todo o período da manhã e do qual muitas vezes não se sentem parte. Lembro de que essa presença negada foi ilustrada por um relato feito durante uma das reuniões pela professora Aliny sobre uma discussão que ela havia feito com os alunos durante uma de suas aulas, abordando a questão da utilização do Laboratório de Informática da escola. Estava-se discutindo o papel que os alunos possuem na preservação do patrimônio escolar, principalmente sobre o laboratório que possui equipamentos relativamente caros e que, por isso, permanece sempre fechado, não sendo utilizado por nenhum professor durante as aulas 
e tão pouco pelos próprios alunos. Em que contexto ocorreu essa conversa com os alunos?

Aliny: Como já disse, eu sempre busco discutir com os alunos sobre vários assuntos e entre eles sempre falo sobre a autonomia e a tomada de decisão que eles precisam exercitar. Um dia conversando com os alunos do primeiro ano do ensino médio, falei sobre a possibilidade de tomarem para si a manutenção e conservação dos ambientes da escola, como por exemplo a biblioteca, a quadra de esportes e o laboratório de informática. Perguntei se eles acreditavam que esses ambientes da escola pertencem a eles e se era responsabilidade deles essa manutenção e conservação. As respostas me surpreenderam e a fala de um deles, "Já que a gente não pode usar os computadores tem mais é que quebrar mesmo!", é bastante emblemática quanto a esse sentimento de exclusão proporcionado pela escola - a frase denota um sentimento de revolta contra aquilo que deveria ser um benefício oferecido pela instituição, mas que é negado aos alunos.

Letícia: É interessante levantar essa questão da degradação dos bens da escola por parte dos alunos e relacioná-la às mesas de pebolim e ping-pong. As mesas foram obtidas pela escola, mas os alunos se sentem donos delas, não as degradam, criam as regras, decidem quando e quem pode jogar e etc. Além disso, as mesas ficam disponíveis no pátio da escola onde todos os alunos têm livre acesso a elas.

Luiz: Percebi a mesma coisa com os experimentos que eles fizeram para a Feira de Ciências.

Thiago: Exatamente! Foi interessante notar que mesmo quando os alunos são liberados mais cedo, quando a aula não se estende até o meio-dia, vários deles permanecem na escola usufruindo da mesa de ping-pong ou de pebolim. Os alunos não querem ir embora. Eles verdadeiramente se apropriaram dessa mesa e se sentem donos dela. E ela está ali, no pátio, acessível aos alunos.

Ângelo: É importante ressaltar isso que o Thiago enunciou. Os alunos entendem a escola como algo além de um campo de formação e aquisição do capital cultural, é um campo social onde eles interagem uns com os outros, se expressam e fazem valer conceitos aprendidos que vão além de matérias prontas. A mesa de ping-pong e o pebolim podem ser só a "ponta do iceberg", pois se dermos mais autonomia (entende-se como usufruir da escola como um todo) para esses alunos a escola só tem a ganhar, pois dali sairão cidadãos conscientes das suas responsabilidades sobre os bens comuns que encontramos ao longo de nossas vidas.

Ualyson: Durante uma reunião do PGP, discutimos o processo de exclusão das pessoas em relação aos bens simbólicos, que estão dispostos no campo, físicos ou propriamente simbólicos, refletindo sobre como os alunos são excluídos dos bens presentes no campo escola. Falamos sobre a biblioteca, a sala de informática, os livros didáticos e a horta da escola. 
Apontamos problemas e demandas presentes na escola, em dado momento falamos sobre o pebolim e a mesa de ping-pong e sobre como os professores decidiram, em certo momento, por esconder esses objetos dos alunos ${ }^{16}$. Concluímos que mais uma vez a escola estava exercendo seu poder e excluindo novamente os bens dos alunos, entretanto era demasiadamente mais violento essa exclusão, pois os alunos já haviam tomado posse desses bens. Decidimos que da mesma forma que queríamos mostrar aos alunos que eles deviam tomar posse dos bens que lhes foram negados, não podíamos negá-los aos bens que eles mesmos reconheciam.

Thiago: Esse discurso vazio de que a escola é pública e, portanto, pertence aos alunos, é um patrimônio deles, não tem efeito algum se não há nenhuma ação concreta que evidencie que esses mesmos alunos de fato pertençam àquele lugar, e que aquele lugar pertença aos alunos. O não reconhecimento (ou não aceitação) desse discurso vazio sobre o patrimônio público, muitas vezes um discurso impositivo, acrítico e não dialógico, apenas reforça o sentimento de realidade negada aos alunos, cujo efeito mais evidente no JBR seja a degradação física e psicológica do ambiente escolar. Desse modo, decidimos trabalhar ações no sentido de minimizar esse sentimento de exclusão que os alunos sentem na escola, tentando torná-la algo que de fato pertença a eles e da qual se sintam parte. Nesse sentido a apropriação dos diversos espaços da escola pelos alunos (a biblioteca, a horta, o laboratório de informática, etc.), se envolvendo em uma ação transformativa real, de impacto significativo no cotidiano escolar se tornou nossa principal estratégia de ação enquanto PGP.

Aliny: Depois de um tempo curto de observação já foi possível perceber as carências que foram destacadas anteriormente. Mas como vocês conseguiram articular as demandas da escola aos Projetos de Investigação Simplificados PIS de cada um e ainda a trajetória de social e escolar de vocês?

Ualyson: Bem, por ter uma vida permeada pelo autoritarismo, este exercido desde o ambiente familiar, reforçado pela formação escolar (principalmente pelos últimos 4 anos da formação escolar básica, $9^{0}$ ano e ensino médio), que se utiliza dos processos de "inculcamento", e por não conseguir enfrentar as estruturas autoritárias impostas sobre mim, "optei" por me adequar a estrutura e internalizar os valores do autoritarismo, da "disciplina" (consequência do colégio militar CPMG) e da competição escolar.

O processo de absorção dos valores descritos foi exponencialmente rápido e reforçado, pois no meu ambiente familiar a esperança de ascensão está na formação escolar. Entretanto as características socioeconômicas da minha família (classe operária, o pai concluiu o ensino médio por meio das provas do ENEM, e a mãe voltou a estudar em um curso técnico, ambos não concluíram os estudos da forma ortodoxa) afastou-o dos centros. Como minha

${ }^{16}$ Atualmente, as duas mesas estão disponíveis para os alunos no pátio da escola. ISSN 2526-2882 
família não reconhecia as escolas da região, me deslocava para as regiões das "boas escolas", para assim conseguir um diploma com maior "significado".

O meu PIS tem como eixo central o papel da escola, como meio de formação e como meio de inculcação de capitais (valores) que demonstram-se longe da realidade de quem usufrui de suas dependências. O campo escola utiliza-se do poder de outorgar o certificado de ensino (diploma) para de certa maneira subjugar os alunos. Estes certificados advêm das relações e atividades construídas dentro do campo escolar, e tem como ferramenta a avaliação como forma de aferir as interações dos alunos na escola. O problema é estabelecer intersecção entre o autoritarismo, o sentimento de exclusão e a avaliação.

Pensando nisso, a proposta é utilizar a avaliação não como ferramenta para aferir o conhecimento, mais sim como uma ferramenta que possibilite aos alunos enxergar as relações dentro do campo escola, e como os mesmos fazem parte disso, visto que avaliar segundo Luckesi consiste em "exprimir um juízo de valor de dados relevantes que promovem uma tomada de decisão”. Logo a intenção por trás do meu PIS é dar aos alunos a ferramenta da avaliação para que os mesmos possam enxergar sua realidade (tomada de dados), exprimir suas opiniões (juízo de valor) e executar alguma atividade que contribua diretamente para sua formação (intervenção). Com base nessa estrutura, os alunos, juntamente com os professores e o corpo administrativo da escola, irão revitalizar e ampliar a horta da escola (é uma demanda da escola que afeta diretamente aos alunos).

Ângelo: Quando falamos em educação não nos detemos em conceitos relacionados apenas ao conhecimento usado para resolver exercícios dentro de sala de aula. Buscamos uma educação em que os alunos façam uso fora da sala de aula também. Qualquer tipo de alfabetização busca essa finalidade, e não é diferente com a alfabetização científica. Quando falamos de ciência fora do contexto escolar, soa como algo apático e de pouca utilidade, feita e praticada por gênios. O principal intuito do meu PIS é demonstrar que não é bem assim que funciona (apesar dos "cientistas" teimarem em manter dessa maneira). Então foi primordial encontrar um problema tão próximo aos alunos para promover essa alfabetização científica. Como já foi dito anteriormente, os alunos não se sentem incluídos nas tomadas de decisões da escola e a sala de informática é um desses problemas. O valor da alfabetização científica será posto à prova, onde segundo Chassot $^{17}$, essa apropriação do conhecimento científico/tecnológico faz com que mulheres e homens possam tornar-se mais ativos nas tomadas de decisões que envolvam ciência e o seu próprio contexto social, ou seja, utilizar-seá do que for apreendido dentro de sala de aula para que os alunos opinem e interfiram em como a ciência ou os bens tecnológicos (sala de informática) vão influenciar na sua formação

\footnotetext{
${ }_{17}$ Attico Chassot, licenciado em química, mestre e doutor em educação. Chassot, A. Alfabetização científica: questões e desafios para a educação. $6^{\mathrm{a}}$ ed. Ijuí: Editora Unijuí, 2014. ISSN 2526-2882
} 
e na dos seus pares.

Mas como temos uma formação, principalmente na física, em que os alunos apenas copiam e simulam exercícios em sala de aula, a matéria tornou-se desgastada, sinônimo de dificuldade e aversão por parte dos alunos-não era diferente comigo durante meu ensino médio. Porém de uma forma um pouco improvável eu passei a me interessar mais por ciência e literatura. As histórias em quadrinhos tiveram grande influência na minha formação escolar e acredito que seu poder globalizador pode facilitar tanto a entrada de conhecimento como a exteriorização do conhecimento, ou seja, é um meio que os alunos terão de se interessar mais pela física, além de utilizarem da linguagem artística das histórias em quadrinhos para se expressarem de forma crítica a respeito do meio em que vivem.

Letícia: Eu estudei toda a minha vida em colégios particulares e tive uma situação financeira muito boa até o $8^{\circ}$ ano. Meus pais têm formação superior, sempre presaram por uma boa educação e me incentivaram a estudar e me dedicar para ingressar numa universidade pública. Mudei-me de volta para Goiânia (após passar 10 anos morando em cidades do interior) para que meus pais recomeçassem a vida em uma pizzaria que eles decidiram abrir, e dois anos depois, após passar por uma crise financeira, eu precisei trabalhar com eles na pizzaria para ajudar a pagar as contas e me manter na escola particular. Sendo assim, desde de nova (cerca de 13 anos) o mundo do trabalho já era uma realidade marcante e importante para $\operatorname{mim}$.

No ensino médio eu gostava bastante de matemática e de física e a minha aula favorita era a de um professor que ensinava a física para além dela mesma, pois ele explica o contexto histórico e como ele influenciava na formação da teoria, levava experimentos, discutia política, religião e etc. Assim a física tornou-se para mim um meio pelo qual era possível discutir e questionar qualquer coisa, dos seus fenômenos às questões sociais que afetavam diretamente a minha vida.

Na universidade fui apresentada, inicialmente, a um trabalho de Bruno Latour (2011), que me permitiu abrir as caixas pretas da tecnociência, mostrando o seu lado político, social e econômico, entre outros.

Quando comecei o estágio e fui para os PGP, decidi usar os conceitos de Latour para discutira tecnociência com os alunos. E ao longo da minha jornada nos diferentes PGP dos quais participei, fiz alterações no meu projeto de modo que eu pudesse discutir o mundo do trabalho e o mundo da tecnociência com os alunos, tendo em vista que um dos meus principais objetivos é a formação de alunos cidadãos críticos capazes de perceber, questionar e alterar o mundo (principalmente o do trabalho, já que é uma realidade na qual todos os alunos se inserirão, mais cedo ou mais tarde) em que vivem.

No JBR, para atender as demandas da escola e dos alunos, para transformar a 
realidade dos mesmos e para ajudar na criação do sentimento de pertencimento à e da escola, incorporei o projeto da feira de ciências ao meu projeto de pesquisa. Nela teremos oficinas (uma delas ministradas por mim sobre artesanato, na qual também trarei discussões sobre o trabalho e dicas para a(o)s aluna(o)s montarem seus negócios), projetos culturais e "científicos" (realizados pelos alunos com orientação dos professores padrinhos e dos integrantes do PGP), além de usarmos a feira como um meio de vender os objetos produzidos nas oficinas e arrecadar dinheiro para fazer algumas "reformas" na escola. A feira também será a culminância dos PIS dos integrantes do PGP.

Thiago: Atacar alguns dos problemas da escola com a colaboração ativa dos alunos parece ser uma importante etapa nesse processo de construção do envolvimento e do sentimento de pertencimento do espaço escolar. A ausência de uma biblioteca em pleno funcionamento, portanto, consiste em uma das misérias (sem aspas, porque é realmente uma miséria que é física e simbolicamente construída naquele espaço por meio da negação permanente de espaços de leitura e escrita) da escola que contribui para reforçar a situação de dominação em que se encontram.

Optei pela biblioteca devido a ampla presença e influência dos livros e da escrita na minha formação. Durante toda a minha formação escolar, inicialmente em escola particular e depois, nos dois anos finais do ensino fundamental e em todo o ensino médio, estudei em escolas que contavam com amplas bibliotecas. Meu envolvimento com a leitura é mais antigo do que com a escrita propriamente dita, em grande parte devido ao meu gosto por histórias em quadrinhos. Acho que grande parte desse gosto atual por livros e pela leitura se deve a esse início relativamente espontâneo na leitura por meio de HQ, as quais possuo o hábito de ler até hoje. Meu contato com a escrita, bem mais recente, inicia-se na segunda metade do meu curso de Licenciatura em Física, com a produção dos primeiros trabalhos para congressos em pesquisa em ensino de física. Hoje, depois de concluir o mestrado, a leitura e a escrita me parecem ser muito importantes de modo que a ausência de meios e acesso à leitura e escrita na escola, objetivados na inatividade completa da biblioteca, me incomodou bastante. Fiquei mais motivado ainda a trabalhar com essa reestruturação da biblioteca quando conheci a sua estrutura e o seu amplo acervo, que permanece inacessível aos alunos. O espanto que os alunos demonstram quando entram na biblioteca, alguns deles ali pela primeira vez apesar de já serem alunos no JBR de longa data, e quando descobrem os livros que deveriam estar disponíveis apenas destacam a falta que ela faz naquela escola.

Logo, a estruturação de uma biblioteca perfeitamente funcional na escola proporciona um espaço e meios para enriquecer a aprendizagem, as discussões a respeito do conhecimento e sobre as próprias condições objetivas de acesso ao mesmo. A intenção aqui é utilizar a biblioteca como um mecanismo de resistência cultural e política (FREIRE, 2011), contra as 
atuais condições objetivas de acesso e usufruto da informação e do conhecimento e, principalmente, contra o aprisionamento da ignorância cultural, política e social incessantemente impostos às regiões populares.

Nesse contexto, uma das ações planejadas junto com o PGP consiste na reorganização, reabertura e revitalização da biblioteca da escola que atualmente encontra-se desativada, abandonada de cuidados, mesmo possuindo um acervo relativamente amplo - contando com cerca de três mil livros. Entre as ideias discutidas chegou-se à conclusão de que a melhor forma de promover essa integração dos alunos com o espaço escolar e promover esse sentimento de posse e pertencimento à escola, seria a de colocá-los participando ativamente nesse processo de revitalização. Apesar de haver uma pequena biblioteca com um acervo considerável na escola, a unidade não possui à sua disposição um profissional bibliotecário responsável por realizar o tratamento técnico adequado ao acervo e que esteja disponível para atender as demandas de professores e alunos na recuperação da informação ali presente. A intenção aqui com esse processo de revitalização da biblioteca é, portanto, suprir essa carência de recursos humanos de apoio a esse importante ambiente, utilizando-se, para tanto, a ajuda dos próprios alunos interessados nessa reestruturação. Dessa maneira, pretendemos fornecer mais uma ferramenta e espaço pedagógicos para que alunos e professores possam usufruir, oferecendo suporte informacional às disciplinas, além de promover a cultura e fomentar a leitura.

\section{Considerações Finais - Algumas Perspectivas}

Aliny: O presente texto teve o objetivo de apresentar as principais problemáticas que fundamentaram a elaboração do Projeto de Intervenção Coletivo (PIC) do PGP-João Barbosa Reis. Tal apresentação se deu a partir de um diálogo entre os agentes mobilizados que buscou resgatar a trajetória da construção do PGP-João Barbosa Reis, evidenciando ainda que essa análise precisa ser efetivamente coletiva e por tanto resgata algumas das impressões e análises de todos os integrantes atuais e pioneiros desse PGP.

Dentro da análise que fizemos, inicialmente destacamos o quanto as preconcepções são influenciadas pela posição que ocupamos no espaço social e, consequentemente, pelas relações que nele conseguimos estabelecer. Muitas vezes, as nossas percepções são influenciadas por opiniões de pessoas que não são capacitadas para opinar sobre as características dessa região (a mídia, por exemplo), mas que, por relações de poder construídas e estabelecidas nesse mesmo espaço social, têm significativo peso e visibilidade. Os relatos, principalmente sobre os receios acerca da região da escola, caracterizam um distanciamento, e uma exclusão, causados pelo desconhecimento, manifestado sob a forma de generalizações que estigmatizam uma periferia marginalizada.

Ainda me incomoda lembrar de quando marcamos a reunião do GGP no JBR e ISSN 2526-2882 
tínhamos que nos preocupar com o horário do início e do fim da reunião porque a escola era muito longe para as pessoas que viriam. Outro fato que me abalou muito e que representa tal afastamento foi quando os estagiários me falavam sobre pessoas que perguntavam se o lugar era muito perigoso e até com que roupas elas deviam ir. Como se o fato de o colégio ser mais afastado já representasse um certo perigo. Essa preocupação com o tempo evidenciou que:

As distâncias físicas podem ser medidas segundo uma métrica espacial, ou melhor, temporal, na medida em que os deslocamentos tomam um tempo mais ou menos longo segundo as possibilidades de acesso aos meios de transporte, públicos ou privados, o poder que o capital, sob suas diferentes formas, dá sobre o espaço é, também, ao mesmo tempo, um poder sobre o tempo (BOURDIEU, 2012, p.163).

A preocupação em combinar meios de caronas, quem iria indicar o caminho, como e quanto tempo para chegar lá, todas essas questões são próprias de um tipo de segregação que é refletido principalmente pela localização geográfica. Localização geográfica essa que garante que o acesso a recursos e serviços sejam dificultados e, portanto, haja uma manutenção da hierarquia de quem pode e quem não pode ter acesso a bens e capitais simbólicos.

Os trabalhos do PGP, por meio de leituras de referenciais teóricos adequados, do enfrentamento da realidade escolar do JBR, o esforço pela identificação e caracterização de demandas, valores e conflitos diversos que permeiam a luta diária pela sobrevivência naquela região, possibilitaram realizar algumas rupturas importantes. Uma delas foi a identificação de uma problemática que, à primeira vista, permaneceu oculta, sublimada em meio às tensões latentes que caracterizam a rotina escolar. Perceber que a escola promove uma exclusão dos alunos que ali estudam não foi uma tarefa simples de se realizar, exigindo um esforço significativo de compreensão das complexas relações que são estabelecidas pelos agentes envolvidos, tanto dentro quanto fora da escola. Atacar o discurso vazio que muitas vezes é empregado de forma cínica para justificar determinadas ações que legitimam (naturalizam) essas exclusões consistem em um dos principais focos dos projetos desenvolvidos no PGP. Para tanto, devemos desconstruir a falácia que se martela na mente dos alunos: "A escola é de vocês".

A (des)construção dessa realidade só pode acontecer quando nos envolvemos efetivamente com o cotidiano da escola e podemos tirar nossas próprias conclusões não só dos problemas encontrados nesse lugar, mas também sobre quais estratégias podemos adotar para contribuir para a mudança desse cenário permeado de preconceitos. Nesse sentido, a ação coletiva do PGP, materializada nos projetos dos estagiários experientes e iniciantes e dos professores formadores envolvidos tentarão dar o melhor encaminhamento possível para minimizar esse processo de exclusão provocado na e pela escola, ao mesmo tempo em que busca engajar alunos e professores a construírem um ambiente mais crítico de ensino e 
aprendizagem, mais resistente a essas falácias - verdadeiros mecanismos de dominação - que entram na escola e se escondem em falsos discursos simplistas.

\section{Referências}

BOURDIEU, P. A reprodução. Petrópolis: Vozes, 2010.

BOURDIEU, P. O senso prático. Petrópolis: Vozes, 2011.

BOURDIEU, P. Efeitos de lugar. In.: BOURDIEU, P. (Org.). A Miséria do Mundo. Petrópolis: Vozes, p. 159-166, 2012.

BOURDIEU, P.; Passeron, J. C. Os herdeiros. Florianópolis: Ed. UFSC, 2014.

BOURDIEU, P.; CHAMBOREDON, J. C.; PASSERON, J. C. Ofício de sociólogo. Petrópolis: Vozes, 2010.

CHASSOT, A. Alfabetização científica: questões e desafios para a educação. $6^{\mathrm{a}}$ ed. Ijuí: Editora Unijuí, 2014.

FREIRE, P. A importância do ato de ler: em três artigos que se completam. São Paulo: Cortez, 2011.

GENOVEZ, L. G. R. Homo magister: conhecimento e reconhecimento de uma professora de ciências pelo campo escolar. 229 f. Tese (Doutorado em Ensino de Ciências) Faculdade de Ciências, UNESP, Bauru, 2008.

LATOUR, B.). Ciência em ação: como seguir cientistas e engenheiros mundo afora. São Paulo: EDUSP, 2000.

\section{Agradecimentos}

Pelo apoio Coordenação de Aperfeiçoamento de Pessoal de Nível Superior (CAPES-PIBID)

\section{Biografia Resumida}

Aliny Tinoco Santos: Licenciada em Física pela Universidade Federal de Goiás (UFG/Campus Samambaia - Goiânia/GO); Professora de Física e Matemática do Colégio Estadual João Barbosa Reis e do Colégio Estadual Novo Horizonte;

e-mail: alinytinoco@gmail.com

Ângelo Antônio Santos de Oliveira: Licenciando em Física pela Universidade Federal de Goiás (UFG/Campus Samambaia Goiânia/GO); Bolsistas do Programa Institucional de Bolsa de Iniciação à Docência-PIBID; Estagiário no Colégio Estadual João 
Barbosa Reis;

e-mail: angelosantos66@gmail.com

Letícia Nunes Andreatta: Licencianda em Física pela Universidade Federal de Goiás (UFG/Campus Samambaia - Goiânia/GO); Bolsistas do Programa Institucional de Bolsa de Iniciação à Docência-PIBID; Estagiário no Colégio Estadual João Barbosa Reis;

e-mail: letyfisica@gmail.com

Luiz Gonzaga Roversi Genovese: Licenciado em Física pela Universidade Estadual Paulista Júlio de Mesquita Filho (Unesp/Rio Claro); Doutor em Educação para a Ciência pela Universidade Estadual Paulista Júlio de Mesquita Filho (Unesp/Bauru); Professor do Instituto de Física e do Programa de Pós-Graduação em Educação em Ciências e Matemática da Universidade Federal de Goiás;

e-mail: lgenovese@ufg.br

Thiago Vasconcelos Ribeiro: Licenciado em Física pela Universidade Federal de Goiás (UFG/Campus Samambaia Goiânia/GO); Mestre em Educação em Ciências e Matemática Universidade Federal de Goiás (UFG); Professor de Faculdade Unicamps

e-mail: thiago.v.ribeiro@live.com

Ualyson Toledo Carmo: Licenciando em Física pela Universidade Federal de Goiás (UFG/Campus Samambaia - Goiânia/GO); Professor de Física e Matemática do Colégio Estadual João Barbosa Reis;

e-mail: ualysontc@gmail.com

Yuri dos Santos Siqueira: Licenciando em Física pela Universidade Federal de Goiás (UFG/Campus Samambaia - Goiânia/GO); Estagiário no Colégio Estadual João Barbosa Reis;

e-mail: yurisiqueirapba@hotmail.com 